\title{
Fungsi Rima dalam Lirik Lagu
}

\author{
M. Hermintoyo \\ Fakultas Ilmu Budaya, Universitas Diponegoro \\ hermintpujangga@gmail.com
}

\begin{abstract}
The lyrics of a song as a creative piece of poetry are made up of physical and mental elements. Physical elements include diction, image, rhetorical means, and rhyme, while the inner element is the meaning. Rima or poetry in the lyrics (poetry) in addition to acting as aesthetics also provides a comfortable atmosphere, fun called eufofoni sound and provide euasana otherwise called kakophoni. Eufofoni sounds in the form of vowel sound, while the sound of kakofoni in the form of consonant sound. The sounds are deliberately chosen by the author as a means of rhetoric to be enjoyed in accordance with the meaning and theme contained in the lyrics. Rima in the lyrics (poetry) aesthetically gives the neatness of sound at the end of the stan neatly with the pattern aaaa (full), abab (cross), abba (hug), aabb (spouse) and broken (abcd).
\end{abstract}

Key word: lirics, poetry, rima, kakophony, aesthetics.

\section{Intisari}

Lirik lagu sebagai karya kreatif seperti puisi terbentuk dari unsur fisik dan batin. Unsur fisik meliputi diksi, imaji, sarana retorika, dan rima, sedangkan unsur batin merupakan maknanya. Rima atau persajakan di dalam lirik (puisi) selain berperan sebagai estetika juga memberi suasana nyaman, menyenangkan yang disebut bunyi eufoni dan memberikan euasana sebaliknya yang disebut kakofoni. Bunyi eufoni berupa bunyi vokal, sedangkan bunyi kakofoni berupa bunyi konsonan. Bunyi-bunyi tersebut sengaja dipilih oleh pengarangnya sebnagai sarana retorika agar bisa dinikmati sesuai dengan makna dan tema yang terkandung dalam lirik tersebut. Rima dalam lirik (puisi) secara estetika memberikan kerapian bunyi di akhir bait secara rapi dengan pola aaaa (penuh), abab (silang), abba (peluk), aabb (pasangan) dan patah (abcd).

Kata kunci: lirik, puisi, rima, kakofoni, estetika.

\section{Pendahuluan}

Lirik lagu sebagai karya kreatif seperti halnya puisi dibentuk oleh beberapa unsur yang terintegrasi terdiri atas unsur fisik dan unsur batin. Yang dimaksud dengan unsur fisik adalah unsur bahasa yang digunakannya. Secara fisik, puisi/ lirik tidak ada tanpa bahasa, sedangkan yang dimaksud dengan unsur batin adalah pikiran atau perasaan yang diungkapkan penyair/ pengarang. Kedua unsur itu saling terkait dan terintegrasi 
membangun sebuah puisi atau lirik secara fungsional (Waluyo, 1987:23). Pradopo (1987:15-20) menyebut unsur-unsur itu dengan strata norma, yaitu (1) starata norma lapis bunyi (sound stratum), (2) strata norma lapis arti (unity of meaning). Lapis bunyi merupakan dasar timbulnya arti.

Unsur pembentuk puisi yang dapat diamati secara visual menurut Aminuddin, (2000a:136) meliputi (1) bunyi, (2) kata, (3) larik, (4) bait, (5) tipografi; yang tidak dapat diamati secara visual, tetapi hanya dapat ditangkap lewat kepekaan batin dan daya kritis pikiran pembaca disebut lapis makna.

Estetika puisi tidak hanya tergantung pada keluasaan ide yang dituangkan oleh penyair dalam karya-karyanya melalui kesatuan kata dan kalimat yang membentuk larik dan bait, tetapi juga bersentuhan dengan bunyi. Jassin (1983:40) menjelaskan bahwa dalam puisi, pikiran dan perasaan sering bersayap, ditambah lagi dengan syarat keindahan bahasa, tekanan suara, bunyi, dan lagu.

Unsur puisi dibina terutama dalam kemerduan bunyi (Ensten, 1984:10). Unsur penting puisi adalah bunyi sebab keindahan puisi dilihat orang sebagai keindahan bunyi (Junus, 1983:131). Bunyi merupakan unsur estetika puisi sebagai tenaga ekspresif. Tenaga ekspresif dalam pengertian ini berarti bahwa bunyi mempunyai tugas untuk memperdalam ucapan, memperkuat nilai rasa, menegaskan suasana, menumbuhkan bayangan angan-angan, dan sebagainya (Pradopo, 1987:22). Slametmuljana (1956:57) mengatakan bahwa bunyi dalam puisi merupakan realitas simbolik. Setiap kata menimbulkan asosiasi dan menciptakan tanggapan di luar arti yang sebenarnya. Hal itu berarti bahwa bunyi yang diungkapkan dengan memanfaatkan gaya bahasa dapat mengarahkan dan memberikan efek perasaan tertentu terhadap puisi.

Wellek (1989:198) mengatakan efek tidak dapat dipisahkan dari makna dan nada setiap baris puisi. Pernyataan tersebut menegaskan bahwa bunyi-bunyi dalam puisi mempunyai peranan penting bagi ekspresi sebab bunyi-bunyi tersebut kecuali sebagai hiasan juga mempunyai fungsi ekspresi dan turut membawa nada, irama, suasana, perasaan, serta gejolak batin penyair. Dalam wacana puitis dikenal adanya eufoni, yaitu rangkaian bunyi yang harmonis dan enak didengar (Sudjiman, 1984:28). Bunyi dapat dipergunakan menganalisis metafora lirik lagu Indonesia populer, seperti bunyi aliterasi, asonansi, eufoni, dan kakofoni. Aliterasi adalah pola persajakan berupa runtun konsonan dalam larik puisi. Aliterasi fungsinya memberikan efek kedalaman ucapan 
dan penekanan ide atau gagasan; asonansi adalah pola persajakan berupa pengulangan bunyi vokal pada kata yang berurutan tanpa disertai ulangan bunyi konsonan. Fungsi asonansi dalam puisi untuk menegaskan perasaan yang diungkapkan penyair; Eufoni adalah kombinasi bunyi yang indah dan merdu dan menggambarkan ekspresi riang gembira, rasa sayang, serta hal-hal yang membahagiakan. Secara umum bunyi eufoni dibentuk kombinasi bunyi vokal /a,e, $i, u, o /$ dan konsonan bersuara /b,d,g,j/, bunyi konsonan liquida $/ r /$, dan $/ l /$, serta konsonan sengau /m,ny,ng/; kakofoni dibentuk melalui kombinasi konsonan $/ k, p, t, s /$ yang mengesankan bunyi-bunyi parau, tidak merdu, dan tidak menyenangkan. Kakofoni dapat memperkuat suasana yang tidak menyenangkan, kacau balau, serba tak teratur, bahkan memuakkan. Dengan kombinasi kakofoni suasana yang kacau balau dan tidak menyenangkan itu menjadi intens (Pradopo 1987:32; Hermintoyo, 2014:14).

Selain bunyi di atas dalam puisi ada bunyi yang teratur di akhir yang dikenal sebagai sajak atau rima. Sajak atau rima ini merupakan kesamaan antarsuku kata dalam puisi (Waluyo1987:90). Sudjiman (1986:64) mengatakan sajak/rima itu adalah pengulangan bunyi yang berselang, baik di dalam larik sajak maupun pada akhir larik sajak yang berdekatan. Kemiripan bunyi antarsuku kata atau pengulangan bunyi tersebut membentuk musikalisasi dan keindahan. Penyair mempertimbangkan persajakan berupa lambang bunyi tersebut untuk memberikan efek atau mendukung perasaan, dan suasana puisi yang diciptakan. Persajakan/ rima ada yang berpola penuh (aaa), silang (abab), berpeluk (abba), dan berpasangan (aabb).

\section{Metode Penelitian}

Metode pemerolehan data dilakukan dengan metode pustaka dengan teknik simak catat. Data diambil dengan teknik purposif sampling. Data berupa lirik lagu populer. Langkah-langkah yang dilakukan dengan mencari lirik lagu di internet atau membeli rekaman lagu yang dibutuhkan dalam penelitian. Selanjutnya didengarkan disimak berulang-ulang; dicatat dan diklasifikasikan.

Analisis data dilakukan dengan mencari unsur intrinsiknya terutama diksi dan rimanya. Karena mengkaji lirik tidak lepas dengan maknanya, untuk memperoleh makna dan keindahannya diperlukan parafrasa. Dalam konsep hermeunetik sebuah teks 
puisi (lirik) harus dicari maknanya dengan memparafrasakan kalimat yang konotatif menjadi denotatif.

\section{Hasil dan Pembahasan}

Kata-kata atau frase metaforis dalam persajakan memberikan keindahan, rasa, suasana, dan kejelasan. Persajakan dapat dimunculkan dengan persajakan (1) silang (abab), (2) penuh (aaaa), (3) sajak berpasangan (aabb), (4) sajak apit/peluk (abba).

Di dalam lirik lagu, persajakan sangat diperlukan agar keharmonian bunyi akhir sesuai dengan nada. Misalnya:

(1) Surya tenggelam di telan kabut kelam

Surya yang muram di hati remuk redam

Jalan berliku jalan kehidupan

Dua remaja kehilangan penawar rindu kasih pujaan

Menempuh cobaan

(Chrisye: Kala Sang Surya Tenggelam

Bait lirik lagu tersebut bersajak penuh (aaa) dan bunyi aliterasi yang menimbulkan efek kakofoni, yaitu suasana tidak nyaman akibat bunyi lam dalam tenggelam, lam dalam kelam, ram dalam muram, dam dalam redam. Efek bunyi memperkuat makna isi puisi tersebut yang menceritakan sepasang remaja tidak mulus dalam percintaannya yang penuh rintangan.

(2) dalam hitam gelap malam

Berdiri melawan sepi di sini di mata ini

Telah terkubur sejuta kenangan

Dihempas keras gelombang

Dan tertimbun batu karang

Yang tak mungkin dapat terulang

Wajah putih pucat pasi tergores luka di hati

Matamu membuka kisah kasih asmara

Yang telah ternoda

(Anggun C Sasmi: Mimpi)

Bait lirik (2) berima patah (abcd) sedangkan bunyi aliterasi membuat bunyi kakofoni yang suasananya tidak nyaman. Ketidaknyamanan terlihat bunyi aliterasi am pada 
dalam, hitam, malam; bunyi as pada dihempas keras. Sesuai dengan isi lirik tersebut pilihan kata menggambarkan kenangan seseorang dalam bercinta yang tidak nyaman, malam tanpa sinar (dalam gelap malam) ada kesepian (berdiri melawan sepi di sini di mata ini). Kenangan itu hanya kenangan dan tidak bisa diulang lagi karena terpaksa berpisah (telah terkubur sejuta kenangan/ dihempas keras gelombang/ dan tertimbun batu karang/ yang tak mungkin terulang). Yang ada sekarang tiada rasa ada luka dan kisah asmaranya telah ternoda (wajah pucat pasi tergores luka di hatil matamu membuka kisah asmaral yang telah ternoda). Pilihan kata hitam, gelap, terkubur dihempas, keras, tertimbun, karang pucat, tergores membuat suasana tidak nyaman. Kata sengaja dipilih selain sebagai estetika juga mendukung tema liriknya.

(3) sejenak kuterlena akan kehidupan yang fana

Nikmat alam semesta nusa indah nirwana

Serasa pagi tersenyum mesra

Tertiup bayu membuka sukma

Adakah hari esok kan tersenyum jua

Memberi hangatnya sejuta rasa

(Chrisye: Sabda Alam).

Pada lirik (3) meskipun berima aaaa (penuh), tetapi bereufoni, yaitu rima akhir dengan menggunakan vokal a pada kata fana, nirwana, mesra, sukma, jua, rasa tidak seperti di lirik (1) yang menggunakan konsonan. Selain sebagai estetika, bunyi tersebut terasa nyaman sesuai dengan isi lirik yang menggambarkan suasana pagi yang nikmat sehingga berharap kenyataan seperti itu akan berlanjut juga pada pagi-pagi berikutnya.

(4) mentari tersaput mega

enggan bersinar

menusuk angin ke raga

jiwa bergetar

(Katon: Terpurukku di sini)

Lirik (4) rima yang digunakan menggunakan rima abab (rima silang), bunyi kakofoni yang tidak nyaman terdapat pada kata tersaput dan menusuk. Lirik itu menjelaskan semangat yang digambarkan dengan mentari, tetapi tersaput mega sehingga menjadi tidak ditemukan rasa semangat bahkan enggan bersinar dan angin menusuk ke raga 
jiwa pun bergetar. Kata yang berakhir dengan konsonan ar pada (enggan) bersinar dan bergetar menjadi semakin tidak nyaman.

(5) ingin kupetik pelangi jadi tiara indah rambutmu

ke jiwa di sinar matamu

walau dunia berhenti berputar

kagumku tiada kan pudar

menembus ruang waktu terbang di antara sang bayu

membumbung ke langit biru kepadamu

kau adalah bidadariku

(Katon: Bagai Bidadari)

Pada lirik (5) rima akhir menggunakan gabungan rima berpasangan $u u$ dan $r r$ dan penggabungannya menjadi rima peluk sebagai unsur estetikanya. Lirik ini menggambarkan betapa kekaguman yang luar biasa perasaannya penuh warna seperti pelangi, ingin dijadikan perhiasan di rambut kekasihnya, di matanya pun akan menjadi pesona, dengan hirup kehidupan penuh cinta yang dalam ( membumbung ke langit biru). Kecantikan kekasihnya tak terhingga seperti bidadari. Bidadari adalah mitos wanita yang cantik dan senpurna. Dalam dongeng diceritakan bidadari adalah wanita-wanita cantik dari kahyangan di negeri antah berantah. Sedangkan dalam agama sering disebutkan bidadari adalah wanita cantik penghuni surga.

(6) mengapa jiwaku mesti bergetar

Sedang musik pun manis kudengar

Mungkin karena kulihat lagi lentik bulu matamu

Bibirmu dan rambutmu yang kau biarkan jatuh bergerai di keningmu

Makin mengajak kuterpana

Kau goreskan gita cinta

Mengapa aku mesti duduk di sini sedang kau tepat di depanku

Mestinya aku berdiriberjalan ke depanmu kusapa dan kunikmati wajahmu

Atau kuisyaratkan cinta tapi semua tak kulakukan

Kata orang cinta mesti berkorban 


\author{
Mengapa dadaku mesti berguncang bila kusebutkan namamu \\ Sedang kau diciptakan bukanlah untukku \\ Itu pasti tapi aku tak mau peduli sebab cinta bukan mesti bersatu \\ biar kucumbui bayangmu dan kusandarkan harapanku \\ (Ebid G Ade: Untuk Sebuah Nama)
}

Data lirik (6) pada bait pertama menggunakan rima campuran. Larik 1-2, 3-4, masing-masing berima penuh, tetapi jika dilihat dari larik 1-2 dan 3-4 berima pasangan ar pada bergetar dan mи pada matamu dan keningmu dengan rima aabb (pasangan). Pada larik 5-6 rimanya patah. Keindahan rima dilakukan hanya pada larik 1,2,3,4. Di larik 1-2 sengaja dipilih diksi yang berakhir ar pada bergetar dan kudengar yang memberikan rasa tidak nyaman akibat pertemuannya dengan yang disayanginya/ mantannya. Getaran asmaranya aibat melihat keacantikan wajahnya (karena kulihat lagi lentik bulu matamu, bibirmu dan rambutmu yang kau biarkan jatuh bergerai di keningmu/ makin mengajak kuterpana) akibatnya timbul lagi perasaan cintanya (kau goreskan gita cinta).

Bait kedua lirik di atas menggunakan rima akhir berpasangan (aabb). Bunyi rima akhir mu u pada di depanmu dan wajahmu dan an pada kulakukan dan berkorban. Selain sebagai aspek estyetika juga memberikan suasana romantis.

Pada bait ketiga, lirik di atas menggunakan rima penuh (aaaaa). Rima akhir $u$ pada namamu, untukku, bersatu, dan harapanku selain memberikan aspek keindahan juga memberikan suasana romantis. Meskipun tidak bisa memiliki, tetapi cintanya tetap ada dengan mencumbu bayangannya dan tidak lagi berharap (sedang kau diciptakan bukanlah untukku itu pasti/ tapi aku tidak mau peduli sebab cinta bukan mesti bersatu/ biar kucumbui bayangmu dan kusandarkan harapanku).

(7) Taman-taman satu-satu lenyap

Pompa bensin datang mengganti

Sawah-sawah satu-satu musnah

Pabrik-pabrik datang melahap 
Pohon-pohon satu-satu roboh

Gunung-gunung satu-satu rubuh

Rumah pongah bertolak pinggang

Pada bukit-bukit sekarat

Orang-orang satu-satu resah

Air-air malu mengalir

Cita-cita satu satu tumbang

Iman iman satu satu gersang

Jalan- jalan satu satu lubang

Orang rajin menggali

Tutup satu gali lagi

Tradisi kotaku tercinta

Dulu kau bernama Paris Van Java

Senyum bunga menyapa ramah

Bandungku sayangm Bandungku malang

Nafasku semakin sesak

(Rita Ruby Hardlann: Bandungku Sayang Bandungku Malang)

Pada lirik (7) rima akhir menggunakan rima patah (abcd) yaitu rima yang tidak beraturan. Aspek estetikanya terletak pada bunyi kata yang diulang-ulang, Pada pilihan kata tertentu ada yang berkakofoni seperti kata lenyap, melahap, sekarat, sesak. Pilihan kata tersebut mempertegas suasana ketidaknyamanan dan kehancuran kota Bandung yang dulu terkenal sebagai kota Paris Van Java Akibat pembangunan, tidak ada lagi suasana hijau yang sejuk dengan pohon-pohonn kini berubah menjadi bangunan rumah; jalan-jalan tidak mulus dan penyelesaiannya hanya permainan untuk mencari untung atau dikorupsi lewat pembangunan jalan. Bandung tidak lagi ramah tetapi membuat nafas sesak. Begitulah kritik dalam lirik itu disampaikan sebagai nasib Bandung yang malang.

(8) Anak-anak menjerit

Asap panas membakar 
Lahar dan badai menyapu bersih

Ini bukan hukuman hanya satu isyarat

Bahwa kita mesti banyak berbenah

(Ebid G Ade: Untuk Kita Renungkan).

Pada lirik (8) rima akhir tidak beraturan menggunakan rima patah (abcd). Bunyi kakofoni terasa pada kata menjerit, membakar, lahar yang menggambarkan betapa dahsyatnya bencana alam. Semua bisa binasa (lahar dan badai menyapu bersih). Lirik ini dibuat agar manusia sadar dengan isyarat dari Tuhan dengan bencana alam agar mawas diri bukan menganggap sebagai hukuman dari Tuhan. Di balik bencana itu manusia harus sadar apa yang telah diperbuatnya pada alam. Alam diberikan Tuhan untuk dimanfaatkan manusia sebagai sarana menunjang kehidupan manusia, tetapi akan menjadi masalah (bencana) jika tidak dimanfaatkan sebagaimana mestinya.

\section{Simpulan}

Lirik (puisi) sebagai karya kreatif secara integratif berwujud unsur fisik dan batin. Unsur fisik meliputi diksi, imaji, rima dan sarana retorika. Unsur ini memberikan dasar unsur batin berupa makna lirik tersebut.

Rima atau persajakan terlihat pada bunyi di akhir bait yang berima aaaa (penuh), aabb (pasangan), abab (silang), abba (peluk) dan abcd patah; ada juga bunyi aliterasi dan asonansi. Bunyi juga memberikan suasana tema lirik tersebut apakah dalam suasana tidak nyaman (eufoni) atau sebaliknya (kakofoni). Bunyi eufoni wujudnya bunyi vokal sangkan bunyi kakofoni wujudnya bunyi konsonan. Selain bermain bunyi sebagai sarana retorika, kata-kata tertentu dipakai dengan mengulang kata sebagai penegasan.

\section{Daftar Pustaka}

Aminuddin. 2000a. Pengembangan Penelitian Kualitatif dalam Bidang Bahasa dan Sastra. Malang: HISKI dan YA3.

Effendi, S. 2002. Bimbingan Apresiasi Puisi. Jakarta: Pustaka Jaya.

Esten, Mursal (Ed.). 1988. Menjelang Teori dan Kritik Susastra Indonesia yang Relevan. Bandung: Angkasa.

Hermintoyo, M. 2014. Kode Bahasa dan Kode Sastra. Semarang: Gigih Pustaka Mandiri. 
Jabrohim (Ed.) 2001. Metodologi Penelitian Sastra. Yogyakarta: Hanindita.

Jassin, H.B. 1983. Tifa Penyair dan Daerahnya. Jakarta: Gunung Agung.

Junus, Umar. 1983. Dari Peristiwa ke Imajinasi: Wajah Sastra dan Budaya Indonesia. Jakarta: Gramedia.

Pradopo, Rahmat Djoko. 1987. Pengkajian Puisi. Yogya: Gajah Mada University Press.

Slametmuldjono dan B. Simorangkir Simanjuntak. 1956. Ragam Bahasa Indonesia. Jakarta: J.B. Walters.

Sudjiman, Panuti.1986. Istilah Sastra. Jakarta: Gramedia.

Waluyo, Herman J. 1987.Teori dan Apresiasi Puisi.Jakarta: Erlangga.

Wellek, Rene dan Austin Warren.1989. Teori Kesusasteraan. (Terj.) Melani Budianta. Jakarta: Gramedia. 